\title{
Blood pressure in 15- to 16-year-old adolescents of different ethnic groups in two London schools
}

\author{
KAY-TEE KHAW* \\ M.Sc., M.R.C.P.
}

M. G. MARMOT $\dagger$
M.B., Ph.D.

*Department of Epidemiology, St Mary's Hospital Medical School, London W2 and + London School of Hygienङ and Tropical Medicine, London WCI

\begin{abstract}
Summary
A blood pressure screening survey was conducted in 357 students, aged 15-16 years, in 2 London schools. Males had higher systolic blood pressures than females, and white males had significantly higher mean systolic pressures than black males, but diastolic pressures were similar. There is no evidence in this survey that blacks have higher mean blood pressures than whites-rather the reverse. This and the difference in blood pressure between schools suggest environmental factors may be important determinants of blood pressure.
\end{abstract}

KEY WORDS: blood pressure, ethnic, children

\section{Introduction}

Studies in the U.S.A. have found higher mean blood pressures in the black compared to the white adult population as well as higher mortality from hypertension-related diseases such as stroke (U.S. National Office of Vital Statistics, 1976). In the United Kingdom, available evidence suggests similar differences: mortality from hypertension and stroke in West Indian and African immigrants is substantially higher than in the native-born in England and Wales (Marmot, Adelstein and Balusu, 1981); Meade et al. (1978) found black factory employees had higher mean blood pressures than white employees, and the Whitehall Civil Service Study (Marmot and Rose, 1983) confirms these differences. These studies were all in adults. There has been speculation that levels of adult blood pressure are determined in childhood. A survey was therefore undertaken to see if ethnic differences in mean blood pressures were discernible in adolescent school children in London.

\section{Methods}

Fourth and fifth year students, aged 15-16 years, were surveyed in 2 ethnically mixed London compre hensive schools, KDC and BHS. Subjects were giver a self-administered questionnaire. After $5 \mathrm{~min}$ rist with subject seated, 2 measures of blood pressuqe (using diastolic phase five) were recorded with $\mathrm{C}_{3}$ random zero sphygmomanometer from the right arm by an observer trained and standardized in blood pressure measurements. There were 2 observers in the survey. The mean of the two readings was used for analysis. Pulse rate, height and weig were also recorded. The surveys in both schools weepe done under standardized conditions by the $s$ me observers.

\section{Results}

Three-hundred and fifty-seven adolescents we seen, an overall response rate of $87 \%$. There were significant differences in sex and ethnic distribution between responders and non-responders.

Males had higher systolic pressures than females (Table 1). White males had significantly higher me systolic pressures than black males but diastolic pressures were similar. These differences were consistent between schools and observers. Black females had higher mean diastolic pressures than whife females in one school. Systolic pressures were similar. Mean blood pressures were significantly differeat between schools, consistent for different sexes and ethnic groups (Table 2).

Systolic and diastolic pressures were significant correlated with height and weight. Adjusting for these factors using regression techniques and analysis of variance abolished the diastolic pressure differences between the white and black females but not the differences in systolic pressure between white and black males, nor differences between schools or sexe. Blood pressure was not related to reported smokimg or alcohol consumption.

BHS school, which had higher mean blood pres sures than KDC, had a higher percentage of pupits 
TABLE 1. Blood pressure (BP) $(\mathrm{mmHg})$ by sex, ethnic group and school [mean (s.d.)]

\begin{tabular}{|c|c|c|c|c|c|c|}
\hline \multirow{2}{*}{$\begin{array}{l}\text { Ethnic } \\
\text { group }\end{array}$} & \multicolumn{3}{|c|}{ KDC School } & \multicolumn{3}{|c|}{ BHS School } \\
\hline & $n$ & Systolic BB & Diastolic BP & $n$ & Systolic BP & Diastolic BP \\
\hline \multicolumn{7}{|l|}{ Males } \\
\hline White & 81 & $114.4(13.6)^{*}$ & $64 \cdot 2(12 \cdot 9)$ & 19 & $119 \cdot 3(11 \cdot 1)^{*}$ & $70 \cdot 1(10 \cdot 1)$ \\
\hline Black & 38 & $108 \cdot 2(11 \cdot 1)^{*}$ & $63.9(11 \cdot 1)$ & 22 & $112.0(16.9)^{*}$ & $72 \cdot 5(11 \cdot 1)$ \\
\hline Other & 12 & $116.7(18.0)$ & $67.4(10.6)$ & 21 & $114 \cdot 7(12 \cdot 6)$ & $70.5 \quad(8.4)$ \\
\hline All & 131 & $112.8(13.6) \dagger$ & $64.4(12 \cdot 2) \dagger$ & 62 & $115 \cdot 1(14 \cdot 0) \dagger$ & $71.1(10.5) \dagger$ \\
\hline \multicolumn{7}{|l|}{ Females } \\
\hline White & 57 & $102.9(13.8)$ & $60.9(9.8)^{*}$ & 20 & $112.9(14.0)$ & $72 \cdot 8(12 \cdot 3)$ \\
\hline Black & 19 & $103.4(9.0)$ & $67.3(11.9)^{*}$ & 39 & $110 \cdot 1(12 \cdot 1)$ & $71.6(10 \cdot 3)$ \\
\hline Other & 4 & $105 \cdot 3 \quad(3.9)$ & $66.3 \quad(7.9)$ & 21 & $110.7(13.3)$ & $71.9(8.7)$ \\
\hline All & 80 & $103.2(12.4) \dagger$ & $62.7(10.5) \dagger$ & 83 & $110.9(12.8) \dagger$ & $71.9(10.3) \dagger$ \\
\hline
\end{tabular}

Student's $t$-test: ${ }^{*} P<0.05$ between ethnic groups; $+P<0.05$ between schools.

TABLE 2. Pulse rate and weight by sex, ethnic group and school [mean (s.d.)]

\begin{tabular}{|c|c|c|c|c|}
\hline \multirow{2}{*}{$\begin{array}{l}\text { Ethnic } \\
\text { group }\end{array}$} & \multicolumn{2}{|c|}{ KDC School } & \multicolumn{2}{|c|}{ BHS School } \\
\hline & Pulse rate $\left(\min ^{-1}\right)$ & Weight (kg) & Pulse rate $\left(\min ^{-1}\right)$ & Weight (kg) \\
\hline \multicolumn{5}{|l|}{ Males } \\
\hline White & $72.0(10.3)$ & $59.7 \quad(9 \cdot 8)$ & $76 \cdot 8(12 \cdot 6)$ & $61 \cdot 8(11 \cdot 7)$ \\
\hline Black & $72.6 \quad(9 \cdot 7)$ & $60.5 \quad(9.0)$ & $70.9(14 \cdot 8)$ & $64 \cdot 2 \quad(9 \cdot 5)$ \\
\hline Other & $74.0(11.7)$ & $61.9(11.6)$ & $76.6(8.9)$ & $52.4(10.0)$ \\
\hline All & $72 \cdot 4(10 \cdot 2)$ & $60 \cdot 1 \quad(9 \cdot 7)$ & $74 \cdot 6(12 \cdot 5)$ & $59.5(11.4)$ \\
\hline \multicolumn{5}{|l|}{ Females } \\
\hline White & $77 \cdot 7(14 \cdot 6)$ & $55 \cdot 1(10 \cdot 3)$ & $87 \cdot 4(16 \cdot 7)$ & $58.6(10 \cdot 4)$ \\
\hline Black & $72.9(12.4)$ & $58 \cdot 1 \quad(8 \cdot 7)$ & $81.9(11.9)$ & $59.6(11 \cdot 1)$ \\
\hline Other & $74.5 \quad(7.5)$ & $55 \cdot 6(14.4)$ & $83.0(12.9)$ & $50.6(10.9)$ \\
\hline All & $76.4(13.9)$ & $55 \cdot 8(10 \cdot 1)$ & $83.6(13.9)$ & $56.8(11.4)$ \\
\hline
\end{tabular}

reporting paternal unemployment, single parent families and positive family history of hypertension. Pulse rates and weights were also higher in BHS. However, these factors did not appear from our data to account for the differences between schools.

\section{Discussion}

The finding that white boys have higher mean pressures than black boys was unexpected in view of higher pressures documented in adult blacks compared with whites. In cross-sectional studies, there are several possible explanations: blood pressure may change differently in different ethnic groups, blacks having a greater rise with age so that mean pressures later diverge. Alternatively, this generation of adolescents may continue to differ from the previous generation with respect to blood pressure. Longitudinal studies are needed to resolve this question. In the U.S.A., ethnic differences have been similarly less consistent in younger age groups (U.S. National Office of Vital Statistics, 1976) and some studies indicate that black-white differences are minimized if factors such as social class or area of residence are controlled for (Harburg et al., 1973). Certainly, the unexpected and unexplained differences between schools in our survey require further investigation.

\section{Acknowledgments}

We are grateful to the headmaster, staff and students of the schools involved, Dr B. Bewlay, Dr D. Birch, Dr B. Edwards, Mrs A. Llwellyn and Professor G. Rose for their help.

Dr M. G. Marmot is partly supported by a grant from the British Heart Foundation.

\section{References}

Harburg, E., Erfurt, J.C., Chape, C., Hauenstein, L.S., SCHULL, W.J. \& SCHORK, M.A. (1973) Socioecological stressor areas and black white blood pressure: Detroit. Journal of Chronic Disease, 26, 595.

MARMOT, M.G., Adelstein, A.M. \& Bulusu, L. (1981) Cardiovascular mortality among immigrants to England and Wales. Postgraduate Medical Journal, 57, 760.

MARmot, M.G. \& Rose, G. (1983) Epidemiology of hypertension. In: Scientific foundations of Cardiology (Eds. Sleight, P. \& Vann Jones, J.) (in press).

Meade, T.W., Brozovic, M., Chakrabarti, R., Haines, A.P., NORTH, W.R.S. \& STIRLING, Y. (1978) Ethnic group comparisons of variables associated with ischaemic heart disease. British Heart Journal, 40, 789.

U.S. National OfFice of Vital Statistics (1976) National Health and Nutrition Survey. Series 11 nos. 4, 5, 135, 163. 